\title{
Mechanical Properties of Laser Welded SS316 and SS321
}

\author{
Muhammed Anaz Khan, A Vivek Anand, Lokasani Bhanuprakash
}

\begin{abstract}
Stainless steel is used in a plenitude of domains from low end applications, like surgical products to high-end applications like aerospace sector. Stainless steels are iron-carbon based alloys with more than $10.5 \%$ chromium. The chromium present in stainless steel has greater affinity towards oxygen atom and will result in the formation of chromium oxide film over the surface at molecular level. Stainless steel grades SS321 and SS316 are considered in this work due to its better flexural rigidity, corrosion resistance and maximum temperature withstanding capacity. The laser beam welding was preferred due to high local energy concentration of the laser beam, which makes it more suitable method for stainless steel welding. Chromium precipitation on the grain boundaries is avoided by using a high laser welding speed that diminishes the exposure of the weld to high temperatures. The microstructure of the welded joints are examined using metallurgical microscope to find out the flaws over the weld joint. Three-point bend test was conducted to quantify the mechanical strength of the welded joints.
\end{abstract} Test

Keywords: Laser Welding, Stainless Steel, Three-Point Bend

\section{INTRODUCTION}

Stainless steel has long been around. Since the 1990s, many manufacturers have been using stainless steel to build skyscrapers, memorials, and even cooking utensils [1-2]. Perhaps we are surrounded by items of stainless steel like saucepans, handrails, pen springs, or watches. The welding process is regulated through laser process parameters such as laser power, and welding speed. The first experiment on austenitic 304L stainless steel sheet is performed by varying the welding speed from 2-10 mm/s and the second experiment is conducted with varying laser power from $300-3500 \mathrm{~W}$ [3-6]. Significance of welding parameters over the geometry of the weld bead, bead diameter, and service cycle were studied from the experimental and analytical approach [7-8]. The optimum parameters of the process associated with

Revised Manuscript Received on July 20, 2020.

* Correspondence Author

Muhammed Anaz Khan*, Department of Mechanical Engineering, MLR Institute of Technology, Hyderabad, India. E-mail: muhammedanazkhan@gmail.com

A Vivek Anand, Department of Aeronautical Engineering, MLR Institute of Technology, Hyderabad, India. E-mail: vivekanandbit@gmail.com

Lokasani Bhanuprakash, Department of Mechanical Engineering, MLR Institute of Technology, Hyderabad, India. E-mail: lokasanibhanu@gmail.com

(C) The Authors. Published by Blue Eyes Intelligence Engineering and Sciences Publication (BEIESP). This is an open access article under the CC BY-NC-ND license (http://creativecommons.org/licenses/by-nc-nd/4.0/) hybrid welding method was evaluated using Taguchi tool [9-13]. Ultimate tensile strength (UTS) is chosen to compare the weld strength of each experimental group. All the welding experiment is repeated three times. Although the procedure was conducted identically, due to the similarity of each parameter and environmental factor, the outcome of the strength test could be different. The influence of various parameters such as welding speed, laser power, beam diameter, focusing distance, power density, and type of shielding gas over welding properties of dissimilar welding combinations such as $\mathrm{Al} / \mathrm{Cu}, \mathrm{Al} / \mathrm{SS}$, and $\mathrm{Al} / \mathrm{Ti}$ [14-16]. In the present work, significance of laser welding parameters such as Power Density $\left(\mathrm{W} / \mathrm{mm}^{2}\right)$, Welding Speed $(\mathrm{mm} / \mathrm{s})$, Laser Power (KW) for SS321 and SS316 steel has been reported.

\section{EXPERIMENTAL WORK}

\section{A. Specimen Preparation}

The 10 sets of specimens are prepared using laser welding process by varying the major power parameters and it is listed in table 1.

Table 1 Laser welding - major parameters

\begin{tabular}{|c|c|c|c|c|c|}
\hline & Speed & Power & $\begin{array}{c}\text { Track } \\
\text { Width } \\
\text { Specimen }\end{array}$ & PD & ED \\
$\mathbf{( m m} / \mathbf{s})$ & $\mathbf{( W )}$ & $\mathbf{( m m )}$ & $\mathbf{( W / \mathbf { m m } ^ { 2 } )}$ & $\mathbf{( J / \mathbf { m m } ^ { 2 } )}$ \\
\hline LW1 & 5.0 & 2700 & 1.79 & 859.87 & 301.33 \\
\hline LW2 & 6.7 & 2800 & 2.02 & 891.72 & 207.92 \\
\hline LW3 & 11.7 & 3000 & 2.26 & 955.41 & 113.78 \\
\hline LW4 & 13.3 & 3000 & 2.00 & 955.41 & 112.50 \\
\hline LW5 & 15.0 & 3000 & 1.88 & 955.41 & 106.38 \\
\hline LW6 & 10.0 & 3300 & 2.50 & 1050.96 & 132.00 \\
\hline LW7 & 11.7 & 3300 & 2.20 & 1050.96 & 128.57 \\
\hline LW8 & 13.3 & 3300 & 2.10 & 1050.96 & 117.85 \\
\hline LW9 & 11.7 & 3400 & 2.30 & 1082.80 & 126.71 \\
\hline LW10 & 13.3 & 3400 & 2.50 & 1082.80 & 102.00 \\
\hline
\end{tabular}

After welding process is completed, the microscopic study is conducted on the specimen using metallurgical microscope. The specimens are prepared for the microscopic study by wire cutting machine. The prepared specimen dimensions is shown in figure 1.

Published By:

Blue Eyes Intelligence Engineering and Sciences Publication (c) Convriaht: All riahts reserved.

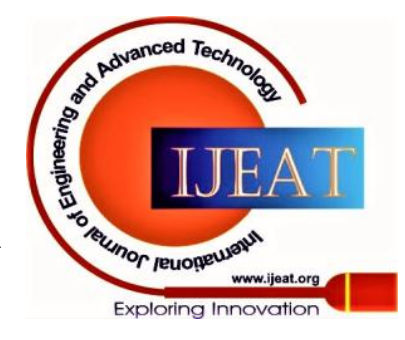




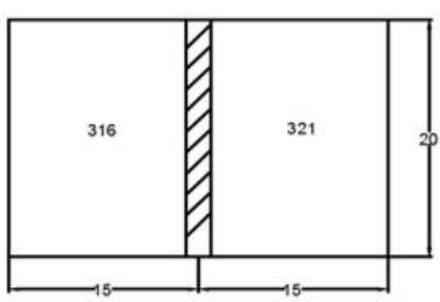

(a)

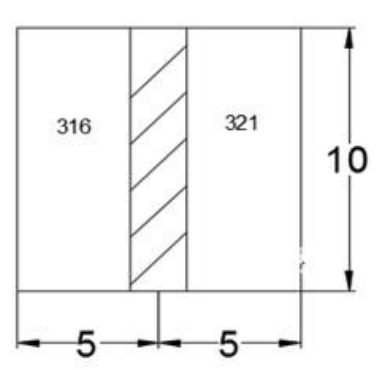

(b)
Fig.1: Specimen Preparation: (a) Metallurgical Microscope and (b) Scanning Electron Microscope

(SEM)

\section{B. Microstructural Characterization}

The as-cast 316 and 321 steel exhibits a fully austenitic microstructure with a homogeneous distribution of intermetallic phases. Laser welding achieved total penetration of joints. Figure 2 demonstrates the macrostructure of weld joints. No cracks and porosities were observed visually, which indicates that the selected laser parameters delivers optimum weld quality. The area of width and fusion is different because of varying laser raster scan speed and power density.

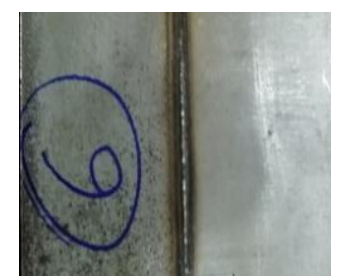

Fig 2: Macrograph of Laser Welded Sample

\section{RESULT AND DISCUSSION}

\section{A. Structural Analysis}

Figure 3 gives the cross-section of $3000 \mathrm{~W}$ laser welded samples treated with differing energy densities of 131, 128 and $117 \mathrm{~J} / \mathrm{mm}^{2}$. For different laser parameters, significant difference in grain morphology is observed across the weld range. A fully refined and columnar dendrites characterize the cross-section. Induced thermal gradient and rate of cooling, regulated through welding speed and laser power, greatly influences the formation of refined grains.

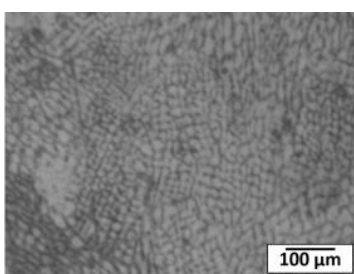

(a)

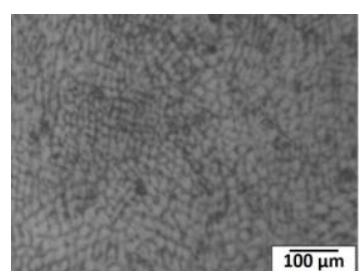

(b)

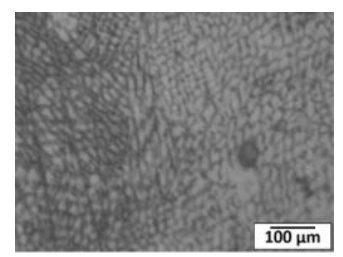

(c)

Fig 3: Optical Microscope (OM) image of (a) LW3, (b) LW4 and (c) LW8 across the weldment.
The microstructure of LW6 shown in figure 4 exhibit a resolidified layer. The cross-section is distinguished through the weld depth by fine equiaxed grains. Uniform grain distribution with different morphologies shows the relationship between laser parameters and grain morphologies.

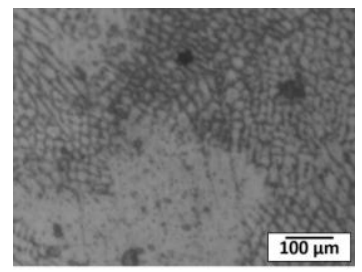

(a)

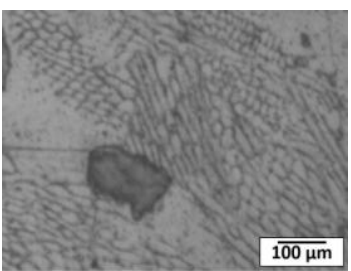

(b)
Fig 4: OM image of (a) LW9, and (b) LW10 across the weldment.

Higher contact time is observed to impart minimal thermal gradient across the molten surface and this induce fine equiaxed grains across the treated depth. A significant variance in grain morphology is observed, while laser power is kept constant. Up to specific depth, fine equiaxed grains were found and coarse grains were observed towards the internal bulk. The reduced contact time gives the treated depth a higher thermal gradient and facilitates the fine equiaxed grains formation. The surface treated with LW9 and LW10 is characterized by finely polished equiaxed grains to a certain d

epth with much reduced grain size, and columnar grains are observed with much reduced primary arm spacing. Higher rate of cooling and thermal gradient was induced due to higher laser power, and lower contact time. This greatly influences the rate of formation of columnar dendrites and promotes the occurrence of graded structure. The temperature and heat gradient increases during the laser scan. This favours the formation of columnar grain formation close to the boundary between treated and untreated area. The thermal gradient angle assumes an inclined orientation with respect to the scan direction. Figure 4(b) shows the growth of column grains inclined towards the scan direction. The results are inline with the image taken using scanning electron microscope which is shown in figure 5.

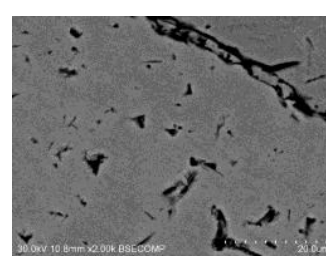

(a)

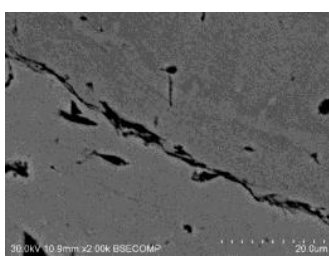

(b)
Fig 5: SEM Image of (a) LW8 and (b) LW7

\section{B. Three Point Bend Test}

In order to study the weld strength and failure mechanism, three-point bend test was performed over laser welded joints. At the weld layer, some interesting features have been found. These include cracks along the weld bead-base material interface, and an oxide surface layer that contains micro-cracks. The source of the micro-cracks may be due to the strains associated with the effect of thermal gradient and rapid cooling that favor thermal stress formation.

Published By:

Blue Eyes Intelligence Engineering and Sciences Publication

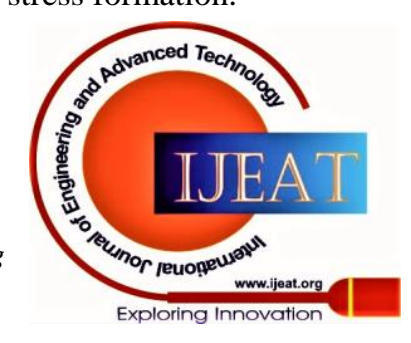


With specimens welded with higher laser power and weld speed, a higher magnification image of the surface shows small holes or voids along the weld. SEM analyzes showed that these cracks are consistent in surface length, form and depth and are aligned perpendicular to the direction of bending as shown in Figure 6.

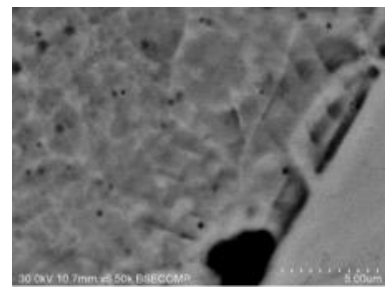

Fig. 6 SEM image along the base material-weld bead interface

As observed from figure 6, the propagation of cracks are attributed through: (i) solidification defect; (ii) Bulk porosity created by trapping the gas or oxygen covering; or (iii) the bending test object. Lower views of magnification showed as dimpled the surface of the voids. The surface micrographs showed that, due to shrinking voids, the holes were created during solidification. Since the surface is stressed, however, cracks have developed along the ground pores periphery. The crack grows perpendicular to the direction of bending and stressed surface which is shown in micrograph. The micrographs are consistent with a crack propagation failure mechanism along the refined grain boundaries as observed in brittle materials when they are stressed beyond the plastic deformation point. The compressive strength results obtained through three-point bend test is given in figure 7. Comparing the test results of LW4, LW5 and LW6, it was observed that, compressive strength increases with energy density. The refinement of cracks resists the propagation of cracks in case of compressive loading. The same was observed for LW6, LW7 and LW8. However, higher laser power and weld speed induce higher thermal gradient, this attributed to the formation of columnar grains having lower columnar spacing. It was observed that higher volume fraction of columnar grains favour the propagation of laminar cracks along the grain boundaries in case of compressive loading.

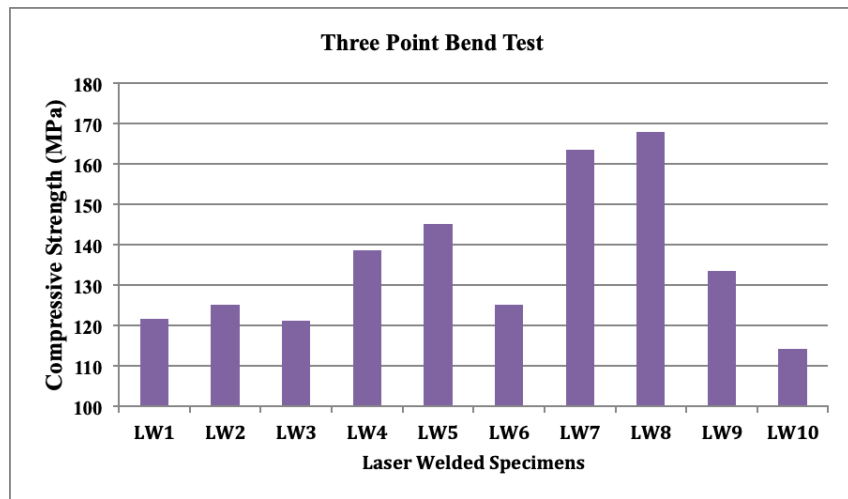

Fig. 7: Compressive strength of laser welded specimens

\section{CONCLUSION}

The following results are drawn from our work.

- Higher scanning speed attribute to the formation of columnar grains through thermal gradient effect.
- For different laser parameters, an apparent difference in grain morphology is noticeable across the weld length.

- Refined equiaxed grains and columnar dendrites were observed across the weld cross-section. Rate of cooling and induced thermal gradient greatly influences the degree of refinement.

- It is possible to observe columnar dendrites extending along the fusion boundary to the center of the weldment.

- Higher contact time is observed to impart lower thermal gradient across the molten surface, thereby facilitating the formation of fine equiaxed grains. There is a noticeable difference in the grain morphology, although the laser energy is maintained continuously.

- $\quad$ Fine equiaxed grains were observed up to certain micrometre depth and coarse equiaxed grains were detected along the inner depth. The reduced contact time gives the treated depth a higher thermal gradient and facilitates the fine equiaxed grains formation.

- LW9 and LW10 weldment is characterized by refined equiaxed grains with fine grain size up to particular depth, below that columnar grains with lower arm spacing were observed.

Formation of columnar dendrites is attributed through higher thermal gradient and rate of cooling due to higher laser power and lower interaction time. It favours the formation of graded structure.

\section{REFERENCES}

1. J. Sun, K. Feng, B. Guo, E. Jiang, K. Zhang, P. Nie, Z. Li, J. Huang, Fiber laser welding of thick AISI 304 plate in a horizontal (2G) butt joint configuration, Mater. Des. 118 (2017) 53-65.

2. Ram GDJ, Reddy GM, Rao KP, Sundar JKS Reddy AV, Microstructure and tensile properties of Inconel 718 pulsed Nd-YAG laser welds. J Mater Process Technol 2005;167:73-82.

3. Hong JK, Kang CY, Park JH, Kim MB, Eom IS, Microstructure and mechanical properties of Inconel 718 welds by CO2 laser welding. J Mater Process Technol 2008;201:515-20.

4. Yilbas BS, Karatas C, Akhtar S, Laser surface treatment of Inconel 718 alloy: temperature and stress analysis. Opt Lasers Eng 2010;48(7-8):740-9.

5. S. Fujinaga, T. Urakami, R. Ohashi, A. Matsunawa, S. Katayama, Development of an all-position YAG laser butt welding process with addition of filler wire, Weld. Int. 19 (2005) 441-446.

6. X. Zhang, X. Shao, P. Jiang, G. Mi, L. Chen, C. Wang, Microstructure and performance of hybrid laser-arc welded $40 \mathrm{~mm}$ thick $316 \mathrm{~L}$ stee plates, J Mater. Process. Tech. 259 (2018) 312-319.

7. K Shiva Shankar, P Sai Prashant, M Ganesh, "Static and dynamic analysis for a swept back dihedral wing and its optimization", IOP Conference Series, Material Science and Engineering 455 (2018).

8. J. Nasstrom, A.F.H. Kaplan, J. Frostevarg, Multipass laser hot-wire welding Morphology and process robustness, J. Laser Appl. 29 (2017) $1-7$.

9. N Madhavi and Rupavath Saritha, "Two bay crack arrest capability evaluation for metallic fuselage", IOP Conference Series, Material Science and Engineering 455 (2018).

10. Liu F, Lin X, Song M, Huang C, Chen J, Yang G, Huang W. The effect of laser scanning path on microstructures and mechanical properties of laser solid formed nickel-base superalloy Inconel 718. J Alloys Compd 2011;509:4505-9.

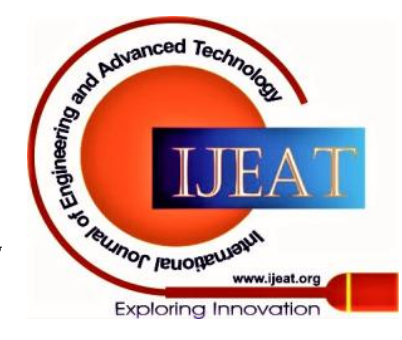


11. J.C. Feng, M.J. Roy, D.W. Rathod, W. Guo, J.A. Francis, N.M. Irvine, A.N. Vasileiou, Y.L. Sun, M.C. Smith, L. Li, An evaluation of multipass narrow gap laser welding as a candidate process for the manufacture of nuclear pressure vessels, Int. J Pres. Ves. Pip. 157 (2017) 43-50.

12. M Sathyanarayana Gupta, Alekhya N, Parthasarathy Garre, P Poornima Reddy and Athota Rathan, "Evaluation of joint properties of friction stir welded al/cu bimetallic lap joints fabricated by threaded tool", International Journal of Mechanical Engineering and Technology 8, 881-888 (2017).

13. W.X. Yang, C. Fang, J.F. Wu, J.J. Xin, J. Wei, W.H. Dai, Y.T. Song, Microstructure and mechanical properties of ultra-narrow gap laser weld joint of $100 \mathrm{~mm}$-thick SUS304 steel plates, J Mater. Process. Tech. 265 (2019) 130-137.

14. M Sathyanarayana Gupta and K Shiva Shankar, "Evaluation of electro-mechanical properties of friction stir welded Al/CU bimetallic lap joints", International Journal of Civil Engineering and Technology 8, 1967-1976 (2017).

15. F. Fetzer, R. Weber, M. Sommer, T. Graf, J.P. Weberpals, Reduction of pores by means of laser beam oscillation during remote welding of AlMgSi, Opt. Lasers Eng. 108 (2018) 68-77.

16. M. Sohail, S.J. Na, S.W. Han, M. Rethmeier, A. Gumenyuk, Numerical investigation of energy input characteristics for high-power fiber laser welding at different positions, Int. J Adv. Manuf. Tech. 80 (2015) 931-946.

\section{AUTHORS PROFILE}

Dr. Muhammed Anaz Khan, is presently working as an Associate Professor in the Department of Mechanical Engineering, MLR Institute of Technology, Hyderabad, Telangana, India. He obtained his Ph.D. from NIT Trichy and is specialized in Material Science and Composite Materials.

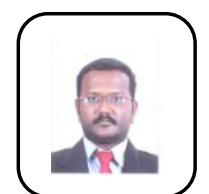

Dr. A Vivek Anand, Professor in the Department of Aeronautical Engineering, MLR Institute of Technology, Hyderabad, Telangana, India. Ph.D. specialization on Wettability and Corrosion Behavior of Micropatterned SS304 Steel in Anna University, Chennai.

Dr. Lokasani Bhanuprakash, is presently working as an Associate Professor in the Department of Mechanical Engineering, MLR Institute of Technology, Hyderabad, Telangana, India. He obtained his Ph.D. from NIT Calicut and is specialized in Material Science and Composite Materials. 